\title{
Guest Editorial: Women's Rights and Children's Rights: Challenges and Opportunities
}

ABSTRACT Judith L. Evans introduces the journal's themes looking at the significant linkages between women's rights and children's rights. Evans argues that the two sets of rights together need to be brought forward, looking at the way they are interlinked through two conventions - CRC and CEDAW - developed in the 1990s. She presents some of the challenges and opportunities that a simultaneous focus on women's and children's rights presents in terms of development work.

KEYWORDS child rearing; civil society; education; health; motherhood; value systems

\section{Introduction}

The Global Movement for Children, initiated by UNICEF, but defined by those who have come together representing NGOs, civil society, academia, foundations and other funders, provides an opportunity for us all to come together and advocate on behalf of children and their families. The messages to be put forward and the strategies developed to do so will represent the considerable knowledge and skills built up by those involved in development work internationally over the last decades. And while the impetus for the Global Movement came from the Special Session for Children to be held on 19-22 September 2001, it is anticipated that the Movement will continue long beyond that date.

One of the significant linkages being made through the Global Movement for Children is between women's rights and children's rights. Even though the needs of women and children are inextricably linked, these two movements have not evolved together; they have been on parallel (and sometimes competing) tracks. 


\section{Where we have come from}

Over the past 30 years there have been considerable developments and shifts in conceptual framing for two important strands of development programming: work with women and work with and for young children. In the 1970s these were known as Women in Development (WID) and Child Survival and Development (CSD) programmes, respectively. Over the past 30 years the work with women has evolved to a focus on gender - referred to as Gender and Development (GAD) - and the work with and for young children has shifted from programming only for survival to increasing attention to children's overall development. This is most commonly known as Early Childhood Development (ECD).

During this time the literature that focused on women's roles in development seldom referred to children, except to mention the need for maternity leave or for child care centres created in support of women's changing roles. Child development journals, on the other hand, generally focused on how to create effective programmes for young children. And, in instances where the focus has been on the youngest children (under the age of three), parents (primarily mothers) are seen as the most natural and most important resource for supporting children's development. However, little or no consideration is given to parents as people in their own right, with their own set of needs and goals.

Nonetheless, from the 1970s to the 1990s these two strands progressed in their understanding of the needs of those they seek to serve. While each began by isolating the woman or the child and addressing their needs and interests in isolation from the family and society, each now takes a more contextual approach to programming, recognizing that people's lives are affected by local and global variables (culture, climate, economic possibilities, governance, etc.). However, for the most part, the expanded conceptualization has not radically changed approaches to programming for either women or children.

One reason for this is that the WID literature in the 1970s distinguished between women's productive roles (those activities that help produce income) and their reproductive roles (activities emphasis on the productive role. This distinction was important from an ideological standpoint; it emphasized that women are not only the producers of the next generation, but are of value in their own right. The unfortunate result of the exclusive focus on production made it difficult for women's programmes to take into consideration women's role in terms of child rearing. It also made it difficult for those designing programmes for young children to find resonance with WID ideology. In turn, it hindered the design of programmes for young children that are supportive of, and permit, the economic and social participation of women in a broad range of activities.

The reality is that women's roles cannot be so neatly divided. For example, the argument can be made that while caring for children (i.e., providing them with the necessary support to ensure healthy growth and development - a child's right) tends to be associated with the reproductive role of women in society, child rearing can also be seen as an economically productive activity. Ironically, when care for children is redefined as 'child care' because it occurs outside the home and/or is paid, it is recognized as an economically productive activity for someone else. However, when child rearing occurs in the home and is unpaid, it is not recognized as such. But whether or not children are raised primarily in the home and whether or not a caregiver is paid, child rearing constitutes a productive as well as reproductive activity.

Not only can caring for children be seen as productive, but mothers are not the only ones that care for children. It is important to recognize that a great deal of the care for children has always occurred outside the home and family in both formal and informal arrangements. It is common, for instance, for the larger community of which families are a part to play a significant role in raising children. This is not only the case for socalled 'traditional' cultures but is increasingly common today as more and more children are being cared for in specialized centres that are not family-run and have nothing to do with family ties.

Thus, to consider care for children only within the context of women's responsibilities limits an understanding of the process and importance of child rearing. The quality of care provided for a 


\section{Evans: Guest Editorial - Women's Rights and Children's Rights}

child affects the child's ability to make a productive contribution to the family and determines the child's chance of becoming productive in later life. Thus those who are involved in rearing children are performing a service to society that has economic as well as social value. Today's children are tomorrow's citizens.

\section{A rights perspective}

In the 1990s a new dimension was added to both women's and children's programming. This was a shift from a needs perspective to a rights perspective. This shift was the result of the development of the Convention on the Rights of the Child (CRC), and the Convention on the Elimination of All Forms of Discrimination Against Women (CEDAW). While the emphasis on rights has the potential to further widen the gap between women's and children's programming, if both sets of rights are taken together it is possible to see that they, in fact, reinforce one another and make mutually supportive demands on society. A comparison of some of the Articles from the two conventions is presented below.

\section{CEDAW and CRC: The complementary rights of women and children}

\section{Rights related to maternal and child health}

Preamble: Bearing in mind the great contribution of women to the welfare of the family and to the development of society, so far not fully recognized, the social significance of maternity . . . should not be a basis for discrimination. . . .

Article 4.2: Adoption by States Parties of special measures, including those measures contained in the present Convention, aimed at protecting maternity, shall not be considered discriminatory.

Article 5 (b): States Parties shall take appropriate measures: to ensure that family education includes a proper understanding of maternity as a social function.

Article 11 (d): To provide special protection to women during pregnancy in types of work proved to be harmful to them.

Article 12.2: States Parties shall ensure to women appropriate services in connection with pregnancy, confinement and the post-natal services . . . as well as adequate nutrition during pregnancy and lactation.

Article 6.2: States Parties shall ensure to the maximum extent possible the survival and development of the child.

Article 24.2: States Parties shall take appropriate measures:

(a) To diminish infant and child mortality

(d) To ensure appropriate pre-natal and post-natal health care for parents.

\section{Family planning}

Article 10 (h): Access to specific information to help ensure the health and well being of families, including information on family planning.

Article 16 (e): The . . . rights to decide freely and responsibly on the number and spacing of their children and to have access to the information, education and means to enable them to exercise these rights.

Article 6.2: Shall ensure to the maximum extent possible the survival and development of the child. Article 24.2 (f): Shall take appropriate measures to develop preventive health care, guidance for parents and family planning education and services.

\section{Child rearing}

Article 11 (c): To encourage the provision of the necessary supporting social services to enable parents to combine family obligations with work responsibilities and participation in public life, in particular through promoting the establishment and development of a network of child-care facilities.

Article 18.2: States Parties shall render appropriate assistance to parents and legal guardians in performance of their child-rearing responsibilities and shall ensure the development of institutions, facilities and services for the care of children.

Article 18.3: States Parties shall take all appropriate measures to ensure that children of working parents have the right to benefit from child care services and facilities for which they are eligible. 


\section{Role of both parents}

Preamble: Aware that a change in the traditional role of men as well as the role of women in society and in the family is needed to achieve full equality between men and women.

Article 5: States Parties shall take all appropriate measures:

(b) To ensure that family education includes a proper understanding of maternity as a social function and the recognition of the common responsibility of men and women in the upbringing and development of their children, it being understood that the interest of the children is the primordial consideration in all cases.

Article 18.1: States Parties shall use their best efforts to ensure recognition of the principle that both parents have common responsibilities for the upbringing and development of the child. ... The best interests of the child will be their basic concern.

\section{Importance/role of traditional culture}

Article 5: States Parties shall take all appropriate measures:

(a) To modify the social and cultural patterns of conduct of men and women, with a view to achieving the elimination of prejudices and customary and all other practices which are based on the idea of the inferiority or the superiority of either of the sexes or on stereotyped roles for men and women. Preamble: Taking due account of the importance of the traditions and cultural values of each people for the protection and harmonious development of the child.

Article 24.3: States Parties shall take all effective and appropriate measures with a view to abolishing traditional practices prejudicial to the health of children.

The dimensions where there is overlap within CEDAW and the CRC can be grouped roughly into four categories: maternal and infant health during pregnancy and birth; care of children throughout childhood/child rearing; the importance and responsibility of both parents; and the importance and role of culture.

\section{Maternal and infant health}

It is during the pre- and post-natal periods that there are the strongest links between women and children. This is understandable, as this is the one time in a child's life when the lives of women and children are inextricably intertwined. Within CEDAW considerable emphasis is given to the conditions that need to be satisfied to ensure the birth of a healthy child from a healthy mother. The Articles in CEDAW and the CRC that reinforce the needs to address the rights of women and children to good health are also reflected in issues related to child spacing and thus to family planning.

\section{Child rearing}

Within both conventions there is recognition of the importance of appropriate care for young children. However, this is a potentially contentious issue, for after the child's first months, there is a range of caregivers who could provide appropriate supports to children's development. And, while in some societies the assumption is made that care needs to be provided by the mother, in fact, in many instances others can and do care for children. Since the issue of who cares for children is a primary concern when creating programmes for women and children, it is worth looking at this assumption in more detail.

For children to survive, grow and develop they need to be nourished, to avoid disease and accidents, to be nurtured and loved, and to learn the ways of the world. Yet the context within which children are being raised is different from culture to culture, and changing continuously. Some of the following dimensions contribute to the changing context:

Economic shifts, including the longer-term trends toward inclusion of all people in a monetary economy, toward cash cropping and toward industrialization have had profound effects on the form and content of child rearing. Economic adjustments in many countries have been accompanied by increases in unemployment, reductions in social expenditures, and the need for poorer families to turn toward self-generated employment in the informal sector, either as a supplement to formal sector earnings or as their sole source of support. 


\section{Evans: Guest Editorial - Women's Rights and Children's Rights}

These policies have helped to continue the trends toward a greater presence of women in the paid labor force, changing occupational distributions within households, and the growth of femaleheaded households.

Over the last two decades, the global cold war has given way to local hot wars and conflicts among and within nations. As a result, the displacement of families has become a problem of major proportions. An important consequence of that problem centres on how to rear children under such conditions.

Migration to urban centres has resulted in a decrease in the number of extended families; the child rearing role of the extended family is diminishing. Moreover, in urban areas the sense of community is now often very weak; the traditional tendency for child rearing to be a responsibility of all community members has been lost.

Declining fertility in recent years has meant smaller families, which means there are fewer children to care for, but also fewer siblings to help with child rearing.

The right of children to attend school has made it less feasible for siblings to participate in child care in a major way.

A result of the above shifts is that women, who are under more pressure to work outside the home, but who, in most cultures, continue to be assigned the responsibility for child rearing, have fewer options than before for help with the child rearing task. It is not surprising, then, that the demand for institutionalized forms of child care should be increasing in most parts of the world. These include pre-schools, crèches, centres for integrated attention to the child, nurseries, and home day care, each with its own characteristics.

\section{The importance and responsibility of both parents}

The role that fathers play in child rearing differs across cultures. At one extreme, one can cite the increase in male one-parent families in the United States or the case of fathers in the Aka group of pygmies in West Africa who have been observed to spend as much as 20 percent of their time holding and interacting with their infant children. At the other extreme are cases in which a high percentage of fathers are absent from the home during the life of a child, either because they have migrated to work (as in many parts of Africa, Latin America and the Caribbean), or because of an increasing divorce rate.

Even when fathers are present in nuclear or extended family arrangements, however, it is common to find that they frequently have little contact with infants and toddlers. When children reach the age of four or five fathers may well be assigned the role of disciplinarian. Fathers also influence the child rearing process indirectly by assuming (or not) the role of economic provider and by providing (or not) emotional support to mothers.

The rediscovery of fathers that seems to be taking place in the United States cannot be exported but there is, nevertheless, a need to bring fathers into the discussion. In some places and in some organizations this is being attempted to by taking 'the family' rather than the individual as both the unit of analysis and the programming unit.

\section{The importance and role of culture}

With changes in the environment come changes in beliefs, values and norms, all of which evolve as the contexts and specific needs of people change. When societies were more or less isolated from one another, child rearing values, beliefs and norms remained relatively stable from one generation to the next. However, few cultures have remained relatively isolated and intact. Most are vulnerable to outside influences - schools, mass media, missionaries, returned migrants - which challenge established values, beliefs and norms.

In the struggle for identity and in the desire to be modern some cultures have completely cast off their traditions, or think they have. Yet many people (indigenous and industrialized, urban and rural) are recognizing that 'modern' ways do not always provide what is best for all concerned. As a result, people are seeking to identify and recapture traditional values. This has resulted in an awareness that much of what existed within traditional 
cultures was positive and supportive of growth and development, for the individual and for the society.

However, the return to more traditional values, beliefs and norms related to child rearing may well have a negative impact on women's other opportunities for development. Many of the healthy child rearing practices are highly mother-reliant; they require the mother's close proximity to the child. For example, within most traditional cultures women breastfeed infants well into the second year of life. The literature suggests that this practice should be continued (or reinstated), at least for a minimum of six months, as this is important for the infant's development. Furthermore, literature suggests that it is best when breastfeeding is done on demand, as it was traditionally. This requires a kind of physical proximity that affects carrying and sleeping practices. Not only does carrying make feeding on demand easier, it is also beneficial for infant development. The physical closeness of mother and child permits, and reinforces, a kind of nurturing that is different from what happens when there is greater physical separation.

However, breastfeeding and carrying practices are at odds with women's work, particularly when that work is outside the home. The great majority of women are not able to take time off from their work to provide the kind of nurturing that is most beneficial for infants. Clearly an understanding of the link between culture and women's and children's rights needs far more attention.

In summary, while CEDAW and the CRC provide some linkages between women's rights and children's rights, neither convention provides an adequate framework that would allow either women or children to develop to their potential. Nor do the conventions define the full range of societal supports that are required for full development to be actualized.

\section{Challenges and opportunities}

A rights perspective offers challenges to advocacy and policy, development programming, and research. Each of these dimensions is discussed briefly.

\section{Advocacy and policy development}

The messages disseminated through advocacy efforts are generally drawn from relevant research and/or are derived from successful projects. Once an appropriate policy is in place, then policy makers, planners and implementers need practical information on how to implement programme components that include complementary and supportive programme strategies that address the rights of both women and children. Many planners are willing to take action, but have no understanding of what is needed or how to accomplish the task.

Thus it can be argued that the lessons learned from research and successful programmes need to be systematized and disseminated. There is the need to write-up case studies describing programmes that have positive results for both women and children. (An example of a very brief case study is presented in Box 1.) In addition, field projects need to be developed in support of the rights of women and children, based on what we know about successful programming.

\section{Development programming: from concept to practice}

A distinction needs to be made between how programmes are conceptualized and how they are implemented. While it is important to conceptualize and design a programme to meet simultaneously the rights of women and children, that may be difficult in practice. There is a greater likelihood of success if a programme starts with one component or the other, but with the early and clear intention of adding additional dimensions. Furthermore, the more participatory the programme structure, the more likely it is that issues of women's and children's rights will be addressed. Experience supports the idea that it is easier to add on child care to women's programmes than the reverse. Women often express the need for child care and are supportive of adding this component.

\section{Research}

Research related to women's and children's rights comes from many fields (health and nutrition, economics, anthropology, sociology, etc.), and is important as the basis for developing policy and actions. 


\section{Self-Employed Women's Association (SEWA)}

SEWA, based in Ahmedabad, India, was begun in 1972. The organization is committed to the empowerment of women, and the creation of autonomous unions organized around women who work in the informal sector (ragpickers, market women, sweepers, etc.). SEWA has always defined its goals in relation to both its work with women on the ground and in terms of creating an "enabling environment' in terms of policy. Thus all projects include components that are a part of delivering a direct service and components focused on policy development and implementation - within the village, the district, and at the national (and even international) levels.

In 1989 SEWA began its work related to child care. Since then SEWA has been organizing and running crèches (for children from birth to three years of age) for women who work in the tobacco industry in rural Kheda District and more recently in urban settings.

When SEWA first began its child care work in the Kheda District it had a dual challenge - the challenge of organizing women working in the tobacco industry, and the challenge of addressing women's needs for child care. SEWA staff soon realized that their two agendas meant that they were sometimes working at cross-purposes. On the one hand they were confronting owners of the tobacco factories, demanding that women receive adequate wages and have proper working conditions, and they were actively organizing the women. On the other hand SEWA was offering a service to the owners, telling them that SEWA would help them conform to the law which required that employers establish crèches for the children of their workers. SEWA workers were pulled in two different directions. One day they wore their organizing hat, and the next they wore their crèche hat. Employers did not know whether to welcome them or shut the door. This led to a great deal of frustration, and neither set of goals was being met. So a new approach had to be developed.

While SEWA continued their work to organize the women, and dealt with the factory owners on issues related to women's work, the approach in terms of child care changed. Instead of trying to work with owners, they began working with the mayors of local villages to establish crèches. This approach met with much greater success on both fronts.

Once things were well underway, SEWA began to see that something else was happening. The creation of a crèche began to draw women to SEWA's work; organizing became much easier. If women wanted to put their children in the crèche, they needed to join the union. Now rather than the crèches being seen as a necessity and a drain on SEWA's time and resources, the crèches have become a vehicle for organizing women. The resulting programme addresses the rights of both women and children.

An example comes from the field of nutrition, where considerable research has been done on the importance of infant care and feeding, particularly during the early months of a child's life. As noted, it is relatively easy to add a child care component to a women's project. This frequently consists of creating alternative child care arrangements so that women can earn income. While care outside the home may be appropriate for children over one year of age, a review of the literature suggests that for children under one year, women should seek the type of work and or the support that allows them to participate in and directly supervise child care. Therefore, we might think of creating ways to 
maintain the income of working mothers in the period following birth. For instance, in Jamaica, market women who have recently given birth continue to prepare at home their basket of goods for sale, then entrust the sale to other traders.

While the research just described illustrates the dimensions that are important in creating programmes based on what we know about children's needs, it is also necessary to conduct research on the impact of early childhood programmes on women. For example, there is a need to sensitize those who are supporting early childhood programmes, to which a great deal of money is being directed, to the importance within their programmes of elements that benefit women.

In most cases, the success of early childhood programmes rests squarely on the shoulders of women. Information about the patterns of use of women's time and the economic implications of the patterns need to be made more available to policy and programme people. If done, this would help build appreciation for the connection between women's economic roles and their supportive role in the child development process.

\section{Conclusion}

In summary, CEDAW and the CRC provide the basis for addressing the rights of women and children within a common framework. From these conventions it can be argued that it is legitimate to support the development of women as women by strength- ening women's roles as mothers. This is being done by providing monetary or work-related rewards for child care and education, recognizing that these activities can be productive as well as personally rewarding. It can also be done by recognizing women's participation in the provision of child care as a valid form of work that should be judged as other jobs are judged in terms of pay, incremental knowledge, skill development, security, training, self-esteem, etc.

On the other hand, it is also legitimate to support children's development by focusing on the development of women in their multiple roles. Those characteristics that facilitate women's overall development also enhance their parenting role. By providing better health, increasing women's educational opportunities, providing access to technical training, ensuring that women have access to income, providing women with credit and land, and freeing women from the long hours required for household maintenance, children's situation will improve.

It can be anticipated that the changing climate generated by activities like the Global Movement for Children will allow women's and children's rights to be brought together in terms of policy and programming, conceptually and practically. But those currently concerned with these issues will have to provide support to the effort through continued research, through dissemination of information about things that work, and through continued advocacy. 